\title{
Kinematic Analysis and Leveling Control Method for a Novel Wheel- Legged Robot
}

\author{
Sun Zhibo, Liu Jinhao*, Yu Chunzhan and Kan Jiangming
}

School of Technology, Beijing Forestry University, Beijing, China

\begin{abstract}
The paper introduces a novel auto-leveling system applied to the obstacle-surmounting robot with six wheellegs. The leveling model of the robot with six wheel legs and one articulated steering is analyzed. Besides, the kinematic model of the robot is presented. In order to optimize the leveling algorithm, a special PID control strategy with the leveling matrix is applied to the leveling system. The experiment shows that the new leveling system can improve the efficiency and the stability of the leveling performance: the leveling time is reduced by 3.5 seconds and the obvious tilt fluctuations are decreased by 5 times.
\end{abstract}

Keywords: Efficiency, kinematic equations, leveling system, wheel-legged robot.

\section{INTRODUCTION}

In recent years, there has been a strong demand for the mobile robots operating on uneven surface [1]. Such equipments have found numerous applications in a wide variety of arenas such as exploration of extraterrestrial, rough unprepared and sharp slope environments $[2,3]$. Wheel-Legged locomotion system is a preferred solution for maneuvering on such rough terrain, e.g. Chariot III [4-8], HyLoS series (four-legged robot) [9], NOROS series [10] and ATHLETE (six-legged robot) [11-13]. Compared with the traditional wheeled machines, high mobility, obstaclesurmounting capability and maneuverability are the major merits of the wheel-leg locomotion system.

With the development of the control technology, automatic leveling system has made great progress $[14,15]$. The system has been widely used in engineering and military arena [16, 17]. Hydraulic method and electromechanical method are two types of driving method applied to the leveling system. The leveling algorithm can be mainly divided into two kinds: location error method and angle error method [18]. Studies [19] show that leveling time can be controlled within 1 minute, and leveling precision can reach within $2^{\circ}$ by automatic leveling system.

Three major factors will impact the performance of leveling system: tracking performance of the support legs, robot structure and leveling method. Due to the special character of the robot, the kinematic model is different from the traditional four-legged structures. In this paper, a novel obstacle-surmounting robot with six wheel-legs is presented. According to the new kinematic model and the classic PID controller, an improved leveling system which has good performance on the leveling efficiency is achieved.

*Address correspondence to this author at the School of technology, Beijing Forestry University Qinghua East Road, Beijing, Postcard: 100083, China; Tel: +8613552276090; E-mail: liujinhao@vip.163.com

\section{STRUCTURE OF WHEEL-LEGGED ROBOT}

This mobile robot is an equipment designed to surmount obstacles actively on forest road. As shown in Fig. (1), the presented robot is a combination of two frames, two rear wheel-legs and four front wheel-legs. The two frames are connected by an articulated shaft [20]. Wheel-legs are attached to the frames and distributed in both sides symmetrically, each with a wheel in the end. The rear wheelleg with one degree of freedom (DOF) is independently actuated by 1 motor (for wheel driving) and 1 linear actuator (for leg lifting). The front wheel-legs are divided into two parts. Each part is a modular with 2 DOF and actuated by 1 motor and 2 linear actuators. In order to cross the obstacle and keep the robot level, the wheel-legs can change the heights when the robot moves on the rough surface.

\section{LEVELING ALGORITHM}

According to the location error method, leveling system actually levels the key points on the surface of the robot [21]. As shown in Fig. (2), four attached joint points between wheel-legs and frames are defined as points $A, B, C, D$. A level plane passing through point $A$ is marked as $A^{\prime} B^{\prime} C^{\prime} D^{\prime}$. The Cartesian coordinate $A-X Y Z$ is established for the leveling kinematic model at point $A$. $Z$-axis is parallel to the direction of gravity. $Y$-axis is parallel to $A D^{\prime}$. And $X$-axis is determined by the right-hand screw rule. When points $B, C$, $D$ rise or fall to fit the plane $A^{\prime} B^{\prime} C^{\prime} D^{\prime}$, the platform is level.

Plane $A B C D$ is related to the plane $A^{\prime} B^{\prime} C^{\prime} D^{\prime}$ by the transformation matrix $T, \operatorname{Rot}(y, \beta)$ defined as rotation of angle $\beta$ along the $Y$-axis, $\operatorname{Rot}(x, \alpha)$ defined as rotation of angle $\alpha$ along the $X$-axis. The corresponding transformation matrix is given in: 


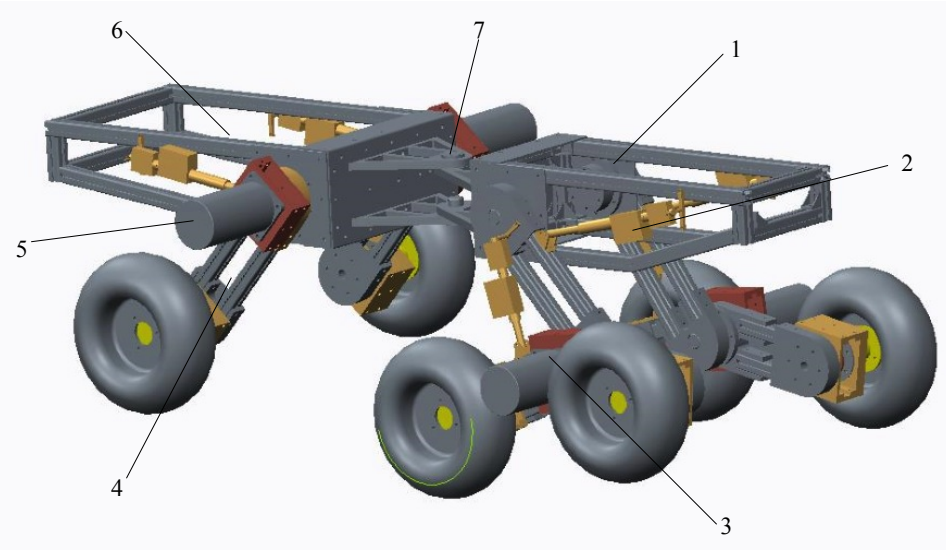

1. Front frame 2. Linear actuator 3. Front wheel-leg 4. Rear wheel-leg 5. Motor 6. Rear frame 7. Articulated shaft

Fig. (1). Structure of the wheel-legged robot.

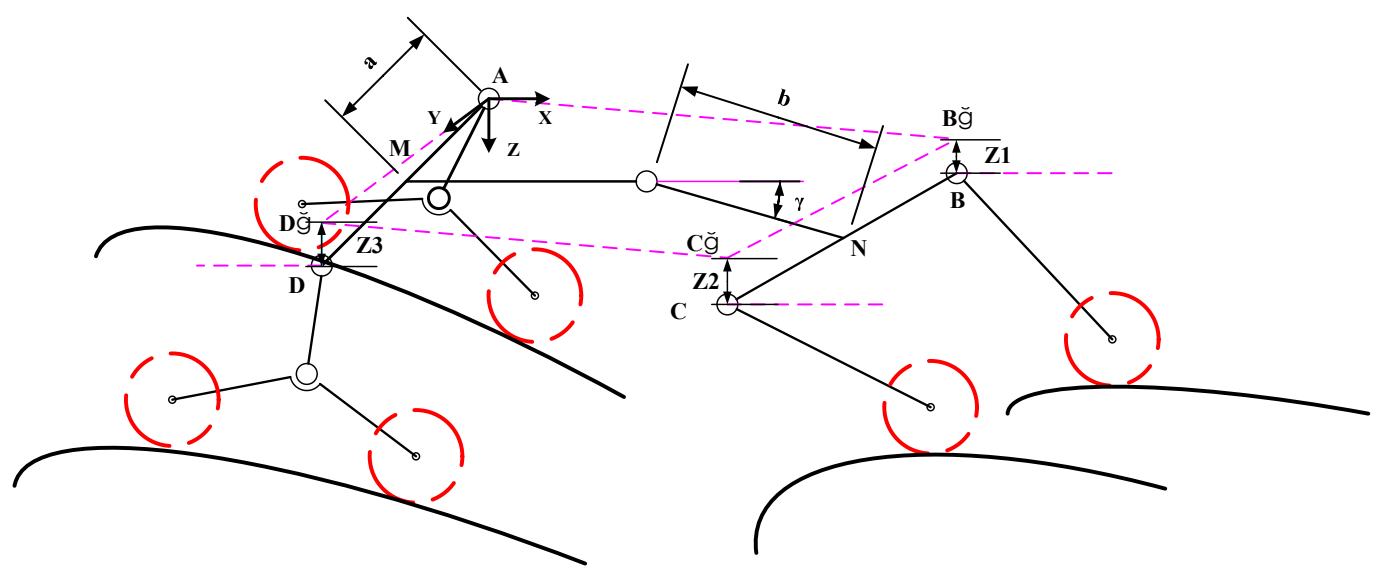

Fig. (2). Leveling model of the wheel-legged robot.

$\mathbf{T}=\operatorname{Rot}(y, \beta) \times \operatorname{Rot}(x, \alpha)=$

$\left[\begin{array}{cccc}\cos \beta & 0 & \sin \beta & 0 \\ 0 & 1 & 0 & 0 \\ -\sin \beta & 0 & \cos \beta & 0 \\ 0 & 0 & 0 & 1\end{array}\right] \times\left[\begin{array}{cccc}1 & 0 & 0 & 0 \\ 0 & \cos \alpha & -\sin \alpha & 0 \\ 0 & \sin \alpha & \cos \alpha & 0 \\ 0 & 0 & 0 & 1\end{array}\right]$

$=\left[\begin{array}{cccc}\cos \beta & \sin \alpha \sin \beta & \cos \alpha \sin \beta & 0 \\ 0 & \cos \alpha & -\sin \alpha & 0 \\ -\sin \beta & \cos \beta \sin \alpha & \cos \alpha \cos \beta & 0 \\ 0 & 0 & 0 & 1\end{array}\right]$

The coordinates of points $A B C D$ are defined as $A$ $(0,0,0), B\left(, x_{b}, y_{b}, z_{b}\right), C\left(x_{c}, y_{c}, z_{c}\right), D\left(x_{d}, y_{d}, z_{d}\right)$, and the initial coordinate matrix is as follow:

$\mathbf{M}=\left[\begin{array}{llll}A & B & C & D\end{array}\right]=\left[\begin{array}{cccc}0 & x_{b} & x_{c} & x_{d} \\ 0 & y_{b} & y_{c} & y_{d} \\ 0 & z_{b} & z_{c} & z_{d} \\ 1 & 1 & 1 & 1\end{array}\right]$

In the leveling model, the coordinates of points $A, B$ ', $C^{\prime}$, $D^{\prime}$ can be obtained as matrix $\boldsymbol{M}^{\prime}$ :
$\mathbf{M}^{\prime}=\left[\begin{array}{cccc}0 & a+a \cos \gamma+b \sin \gamma & a+a \cos \gamma-b \sin \gamma & 0 \\ 0 & b-b \cos \gamma-a \sin \gamma & b+b \cos \gamma-a \sin \gamma & 2 b \\ 0 & 0 & 0 & 0 \\ 1 & 1 & 1 & 1\end{array}\right]$

where $\gamma$ is the articulated steering angle, $a$ is half length of the straight line $A D$, and $b$ is half length of the polyline $M N$.

Based on coordinate transformation equation [22], the matrix $\boldsymbol{M}^{\prime}$ can also be described as following:

$$
\mathbf{M}^{\prime}=\mathbf{T} \times \mathbf{M}
$$

The difference of vertical distance $\Delta \mathbf{z}$ can be calculated as follow:

$\Delta \mathbf{z}=\left[\begin{array}{c}z_{b} \\ z_{c} \\ z_{d}\end{array}\right]=$

$\left[\begin{array}{c}(a+a \cos \gamma+b \sin \gamma) \cos \alpha \sin \beta-(b-b \cos \gamma-a \sin \gamma) \sin \alpha \\ (a+a \cos \gamma-b \sin \gamma) \cos \alpha \sin \beta-(b+b \cos \gamma-a \sin \gamma) \sin \alpha \\ -2 b \sin \alpha\end{array}\right]$ 


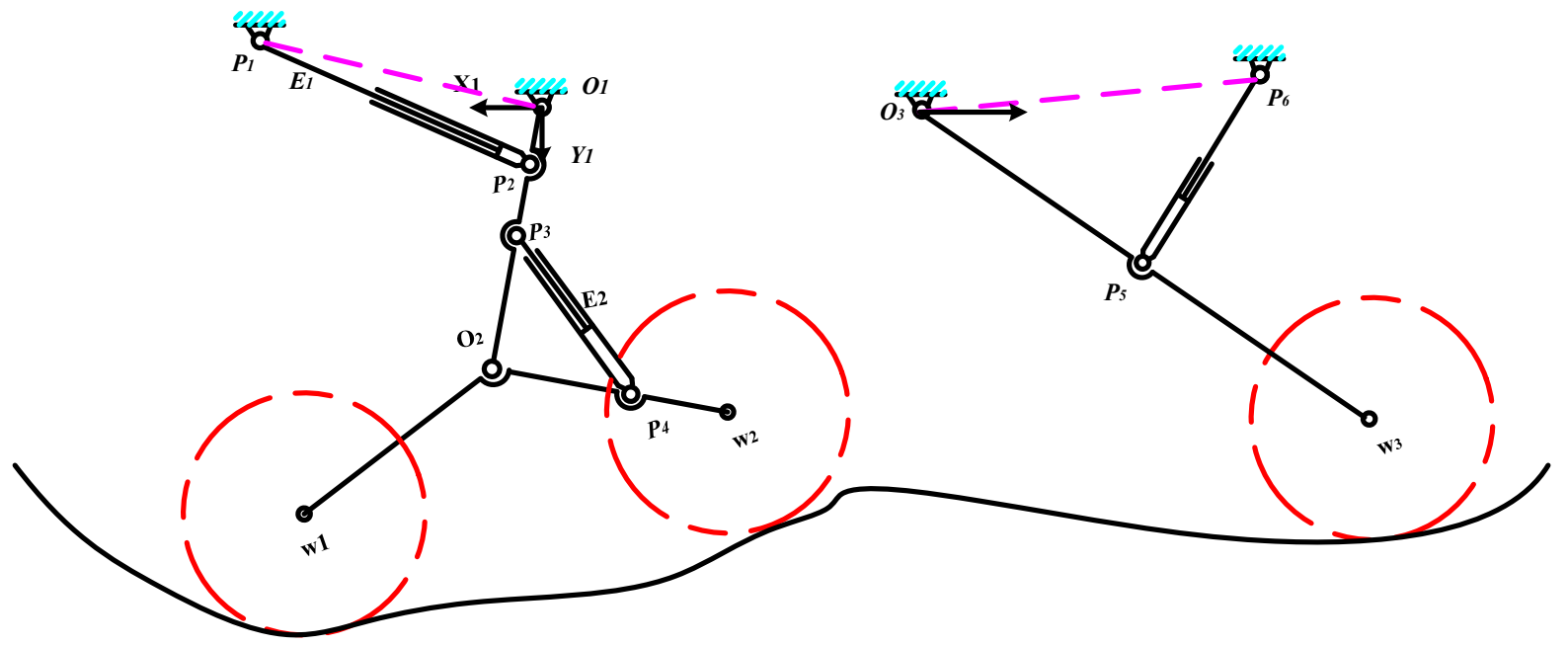

Fig. (3). Kinematic model of one side wheel-legs.

Fig. (3) shows the kinematic model of wheel-legs on one side of the frame. In the model, coordinate system $X_{l} O_{I} Y_{l}$ is established. In order to make the relationship clear, relevant parameters are defined, as can be seen in Table 1. Based on the law of cosines, a group of constraint equations are as follow:

$$
\left\{\begin{array}{l}
\cos \left(\theta_{1}+\lambda_{1}\right)=\frac{s_{1}{ }^{2}+s_{2}{ }^{2}-E_{1}{ }^{2}}{2 s_{1} s_{2}} \\
\cos \theta_{2}=\frac{s_{3}{ }^{2}+s_{4}{ }^{2}-E_{2}{ }^{2}}{2 s_{3} s_{4}} \\
\cos \left(\theta_{3}+\lambda_{2}\right)=\frac{s_{5}{ }^{2}+s_{6}{ }^{2}-E_{3}{ }^{2}}{2 s_{5} s_{6}}
\end{array}\right.
$$

The vertical coordinate of the wheel center plays an important role in the frame leveling system, which is determined by $\theta_{1} \theta_{2} \theta_{3}$. A group of constraint equations is as follows:

$$
\left\{\begin{array}{c}
y_{w 1}=l_{1} \cdot \cos \theta_{1}+l_{2} \cos \left(\theta_{2}+\phi-\theta_{1}\right) \\
y_{w 2}=l_{1} \cdot \cos \theta_{1}+l_{2} \cos \left(\theta_{2}-\theta_{1}\right) \\
y_{w 3}=l_{3} \cdot \cos \theta_{3}
\end{array}\right.
$$

The kinematic equation between vertical velocity of the wheel center and the velocity of the angle is as follow:

$$
\dot{\mathbf{y}}=\mathbf{J}(\theta) \cdot \dot{\theta}
$$

where, $\quad \dot{\mathbf{y}}_{w}=\left[\begin{array}{ccc}\dot{y}_{w 1} & \dot{y}_{w 2} & \dot{y}_{w 3}\end{array}\right]^{T}, \quad \dot{\theta}=\left[\begin{array}{lll}\dot{\theta}_{1} & \dot{\theta}_{2} & \dot{\theta}_{3}\end{array}\right]^{T}$. From Eqs. (4) and (5), the $3 \times 3$ Jacobian matrix $\mathbf{J}(\theta)$ can be extracted as:

$$
\mathbf{J}(\theta)=\left[\begin{array}{ccc}
l_{2} \sin \left(\phi-\theta_{1}+\theta_{2}\right)-l_{1} \sin \theta_{1} & -l_{2} \sin \left(\phi-\theta_{1}+\theta_{2}\right) & 0 \\
l_{2} \sin \left(\theta_{2}-\theta_{1}\right)-l_{1} \sin \theta_{1} & l_{2} \sin \left(\theta_{1}-\theta_{2}\right) & 0 \\
0 & 0 & -l_{3} \sin \theta_{3}
\end{array}\right]
$$

The velocity of the angle which is determined by the velocity of the actuator, can be written as follow:

$\dot{\theta}=\mathbf{J}(E) \cdot \dot{\mathbf{E}}$

where $\dot{\theta}=\left[\begin{array}{lll}\dot{\theta}_{1} & \dot{\theta}_{2} & \dot{\theta}_{3}\end{array}\right]^{T}, \quad \dot{\mathbf{E}}=\left[\begin{array}{lll}\dot{E}_{1} & \dot{E}_{2} & \dot{E}_{3}\end{array}\right]^{T}$. From eqs. (3) and (6), the $3 \times 3$ Jacobian matrix $\mathbf{J}(E)$ can be extracted as:

\begin{tabular}{|c|c|c|c|c|c|c|c|c|c|c|c|c|}
\hline Marked in Fig. (3) & \multicolumn{4}{|c|}{$\angle P O X$} & \multicolumn{2}{|c|}{$\angle P O-X$} & \multicolumn{3}{|c|}{$\angle w_{z} O_{z}$} & $\angle X O P$ & $\angle P O P$ & $\angle-X O P$ \\
\hline Parameters & \multicolumn{9}{|c|}{ Fixed Length } & \multicolumn{3}{|c|}{ Length of Actuators } \\
\hline Parameters & $s_{i}$ & $s_{3}$ & $s_{1}$ & $s_{\text {. }}$ & $s_{s}$ & $s_{s}$ & $l$ & $l$ & $l$ & $E_{\mathrm{t}}$ & $E_{i}$ & $E_{\text {, }}$ \\
\hline
\end{tabular}

$\mathbf{J}(E)=I_{3} \cdot\left[\frac{E_{1}}{s_{1} s_{2}}\left(1-\left(\frac{s_{1}{ }^{2}+s_{2}{ }^{2}-E_{1}{ }^{2}}{2 s_{1} s_{2}}\right)\right)^{-\frac{1}{2}} \frac{E_{2}}{s_{3} s_{4}}\left(1-\left(\frac{s_{3}{ }^{2}+s_{4}{ }^{2}-E_{2}{ }^{2}}{2 s_{3} s_{4}}\right)\right)^{-\frac{1}{2}} \frac{E_{3}}{s_{5} s_{6}}\left(1-\left(\frac{s_{5}{ }^{2}+s_{6}{ }^{2}-E_{3}{ }^{2}}{2 s_{5} s_{6}}\right)\right)^{-\frac{1}{2}}\right]^{T}$

The velocity relationship between wheel center and the actuator is deduced from Eqs. (5) and (6). The resulting equation is as follow:

Table 1. Parameter definition of one side wheel-legs. 
$\dot{\mathbf{E}}=\mathbf{J}(E)^{-1} \cdot \mathbf{J}(\theta)^{-1} \dot{\mathbf{y}}_{w}$

On the other side of the robot, the second kinematic equation between wheel center and the actuator can be obtained as:

$\dot{\mathbf{E}}^{\prime}=\mathbf{J}^{\prime}(E)^{-1} \cdot \mathbf{J}^{\prime}(\theta)^{-1} \dot{\mathbf{y}}_{w}^{\prime}$

Different positions are corresponding to different velocities in the leveling system. In order to accelerate the leveling speed and improve the leveling accuracy, the speeds of the actuators should be changed with the vertical distances. According to the different center positions of the wheels, the vertical distance matrix is defined as $\Delta \mathbf{z}^{\prime}=\left[\begin{array}{llllll}z_{b} & z_{b} & z_{c} & z_{d} & 0 & 0\end{array}\right]^{T}$. By combining Eq. (7) and Eq. (8), the leveling matrix is derived as:

$\mathbf{J}(L)=\left[\begin{array}{cc}\mathbf{J}(E)^{-1} \cdot \mathbf{J}(\theta)^{-1} & 0 \\ 0 & \mathbf{J}^{\prime}(E)^{-1} \cdot \mathbf{J}^{\prime}(\theta)^{-1}\end{array}\right]$.

The momentary speed variations of the actuators are calculated by the post-multiplication of the leveling matrix and the vertical distance matrix.

\section{CONTROL STRATEGY AND SIMULATION}

The level of the frames is determined by motions of the wheel-legs all the time, so level control system should be designed with strong robustness. Closed loop feedback PID control system is adopted as the leveling control strategy, as shown in Fig. (4). Articulated steering angle and tilt-angles of $X$-axis and $Y$-axis are the parameters input into the system. The system controls linear actuators extended or shortened by the signals sent from PID-controller. So the leveling of the frames is achieved.

According to the control strategy, model of the control system is simulated by the combination of Simulink and Adams. The structure of the simulation is shown in Fig. (5).

Initial position of the robot is set as: $\alpha=15^{\circ}, \beta=10^{\circ}$, $\gamma=20^{\circ}, s_{1}=636 \mathrm{~mm}, s_{2}=191 \mathrm{~mm}, s_{3}=447 \mathrm{~mm}, s_{4}=217 \mathrm{~mm}$, $\theta_{1}=25^{\circ}, \theta_{2}=37^{\circ}$. The parameters are input into the simulation system. Fig. (6) shows the simulation process in Adams. As the result, velocities of the linear actuators and changes of tilt-angles are obtained, which is shown in Fig. (7).

\section{LEVELING TEST OF THE ROBOT PROTOTYPE}

\subsection{The Experimental System and Method}

The entire test system consists of 3 parts: control system, performing system and detecting system. As can be seen in Fig. (8), control system includes power supply, 2 tilt sensors and EPEC controller; performing system contains the linear actuator and the actuator power supply; detecting system is comprised of ADIS IMU (inertial measurement unit) and PC. The control system is programmed by Codesys.

The process of the test is as follow:

1. Connect control system, performing system and detecting system, and ensure the system running well.

2. Reset all of the actuators, and ensure the frames are level.

3. Adjust the installation positions of the two tilt-angle sensors and ADIS IMU, and then make sure the output degrees of $X$-axis and $Y$-axis tilt-angles are both $0^{\circ}$, and the output acceleration signal of the ADIS IMU only has value in Z-axis.

4. Tilt the body $15^{\circ}$ with $\mathrm{x}$-axis and $10^{\circ}$ with $\mathrm{y}$-axis, and turn the rear frame to make articulated steering angle $20^{\circ}$.

5. Load traditional leveling program (without leveling matrix) and the improved leveling program (with the leveling matrix) respectively, experiment 2 times with each method and read the data of ADIS IMU from PC.

\subsection{Analysis of Experimental Results}

As can be seen in Fig. (9), the leveling performance is significantly enhanced by the improved leveling system. Compared with the traditional one, the improved method

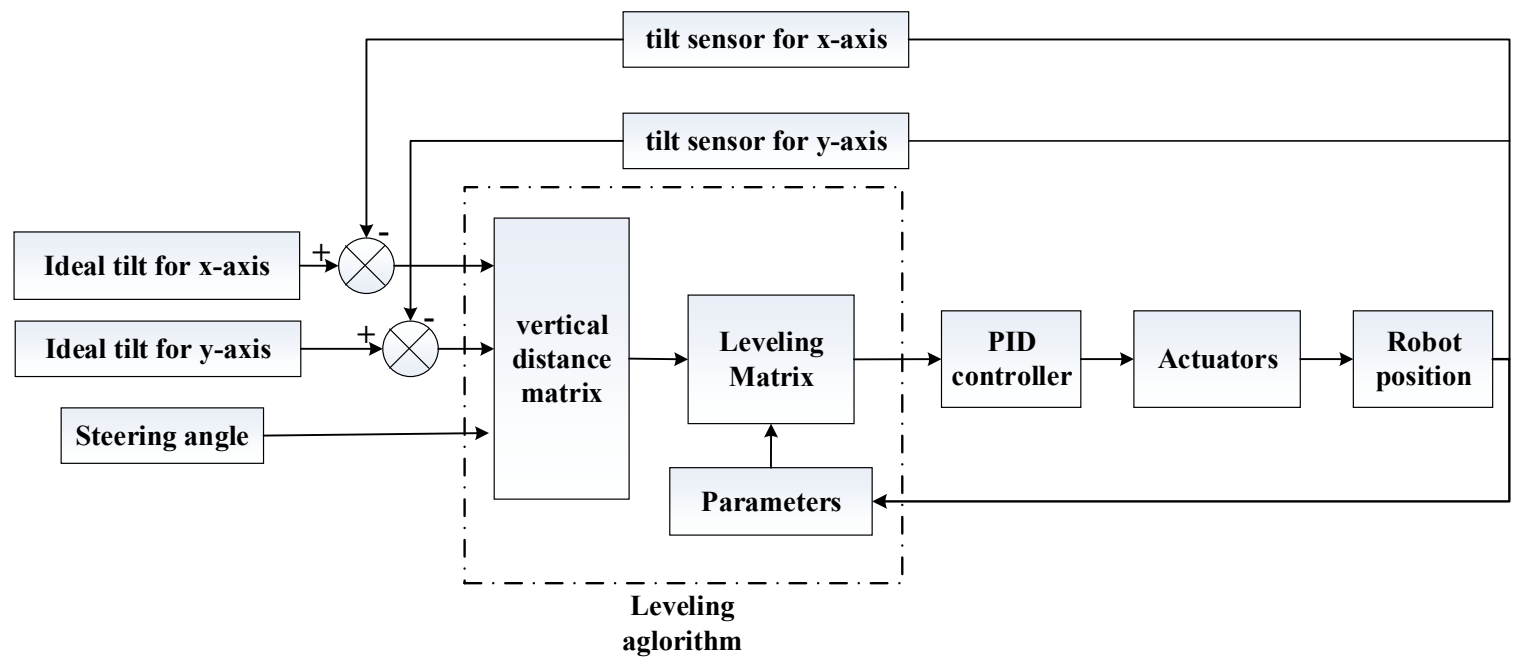

Fig. (4). Control strategy of the leveling system. 


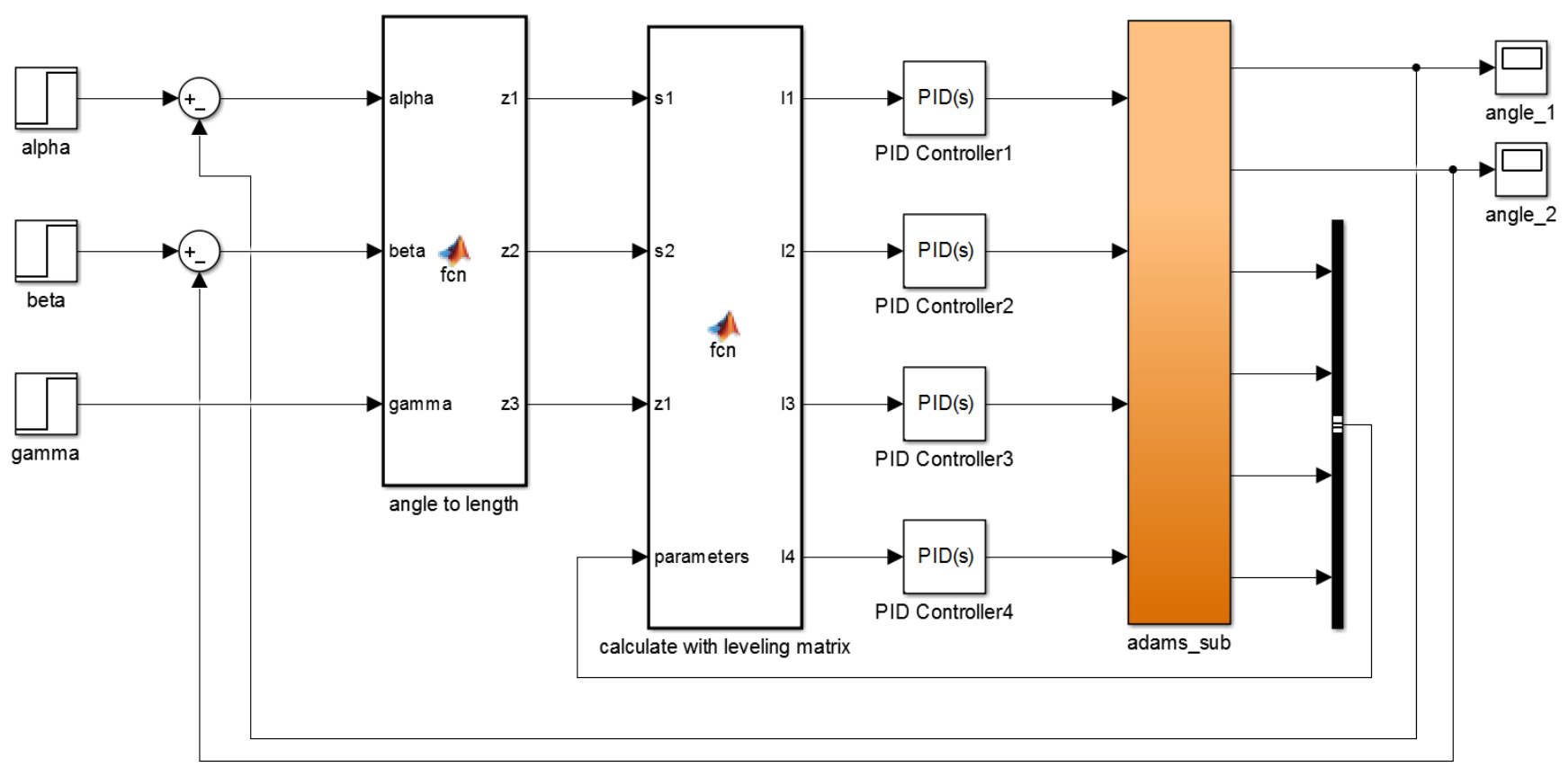

Fig. (5). Structure of the leveling system simulation.
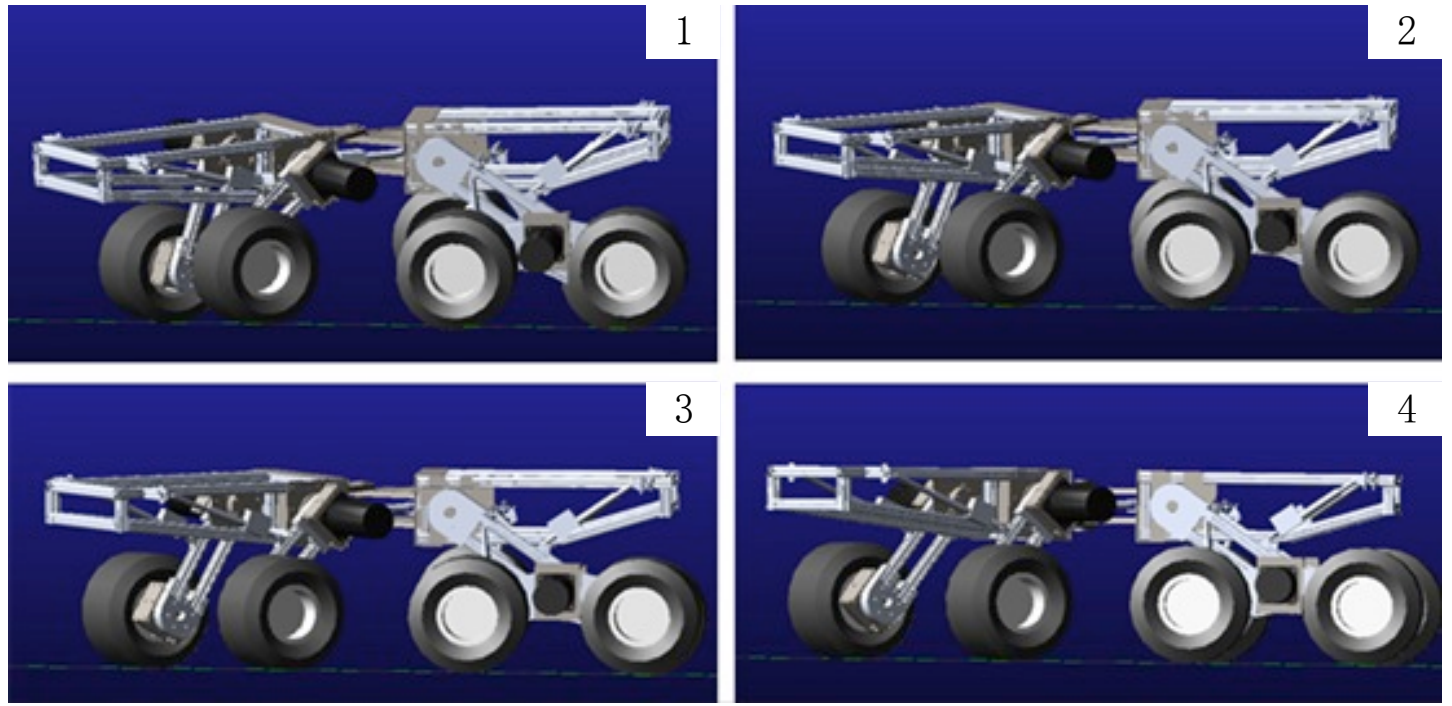

Fig. (6). Leveling process of the robot in Adams.

reduces the fluctuation of the tilt-angles at the early time. After 5 seconds, the leveling speed of the improved system is obviously quicker than that of the traditional method.

Figs. (10, 11) show the the leveling rate through the leveling process. The data are obtained by differentiation processing of the tilts. It is clear that the leveling rate has changed gently after improvement.

As shown in Table 2, statistics suggests that the improved method can reduce leveling time by 3.5 seconds and obvious tilt fluctuation (Amplitude exceeded 1 degree/s) by 5 times( 2 times for $\mathrm{x}$-axis and 3 times for $\mathrm{y}$-axis).

Through the results of the experiment, some conclusions can be obtained as follows:

1. The new method with leveling matrix can really improve the leveling performance, which may be attributed to the following reasons:

(1) At the beginning of the leveling, actuators run quickly. The improved method reduces the contact exchange times between wheels and ground by enhancing the cooperation of the actuators. So the improved method can reduce the fluctuations of the tilt-angles at the early time

(2) From 5 to 10 seconds, actuators slow down with different rates, as shown in Fig. (7). The improved method which involves leveling matrix can adjust the velocities of the actuators more accurately and the leveling efficiency is improved at the same time. 


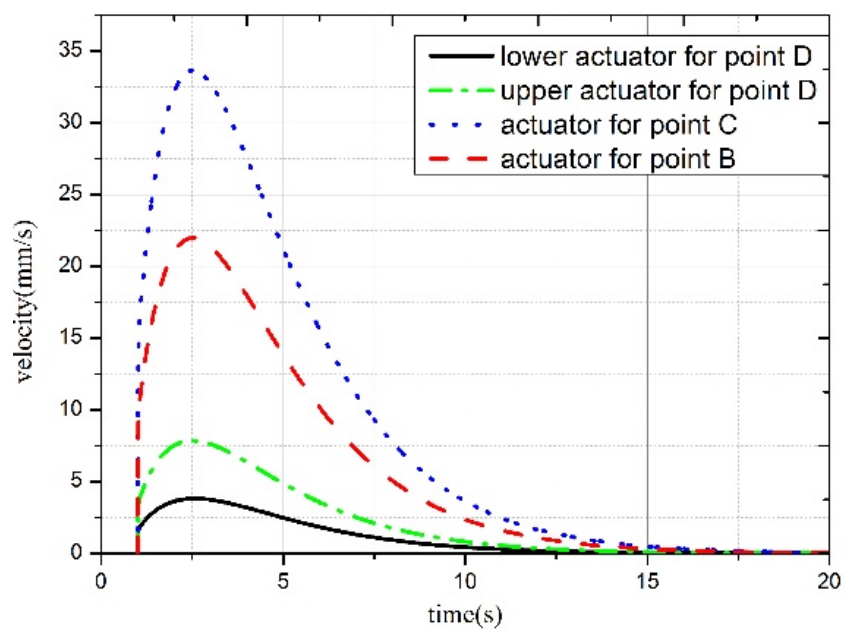

(a) Velocities of the linear actuators

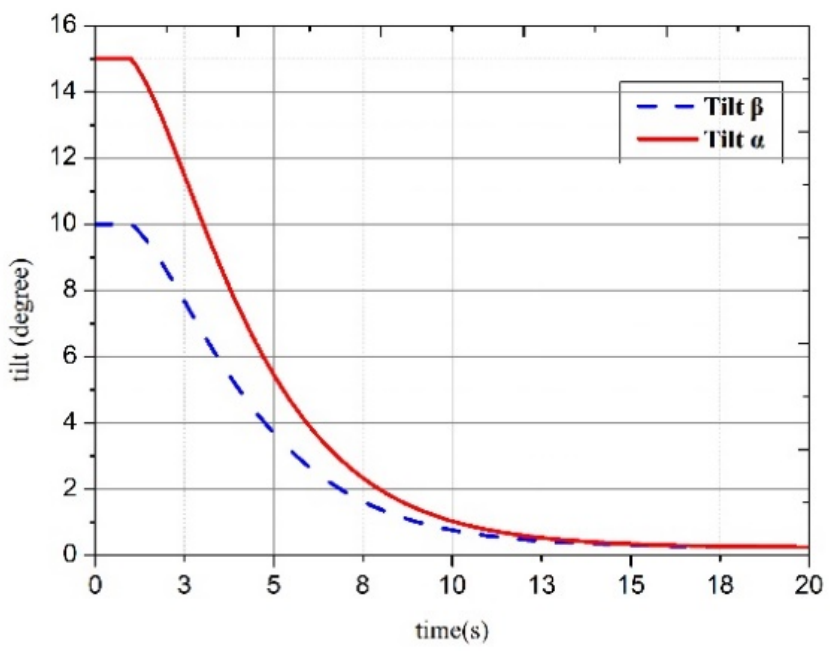

(b) Changes of tilt-angles in simulation
2. At the end of the experiment, both methods show almost the same leveling accuracy and the leveling error can reach within $1^{\circ}$. It proves that the final leveling precision is irrelevant to the leveling method, but mainly depends on the devices in the system.

3. The validity of simulation for the leveling system is verified by the experiment. The data in Fig. (9) fit well with that in Fig. (7), and the fitting degree is above $85 \%$. Vibration of the tires may be the main reason of the error.

\section{CONCLUSION}

In this paper, a novel six-wheel-legged robot is presented. In order to keep the body remain level when it stands on the uneven road, the kinematic model of the robot leveling system is achieved based on the kinematic equations. With the new leveling algorithm, a special PID control strategy is applied to the leveling system. According to the result of the simulation by Simulink and Adams, the control strategy is proved to be viable in the leveling system. The improved method seems to be an effective way of the leveling system. The test result shows that leveling time can be reduced by 3.5 seconds(21\%) and obvious tilt fluctuation can be decreased by 5 times(35\%) with the leveling matrix applied to the leveling system.

There are also some inadequacies of the leveling system which can be improved in the future.1. The vibration between the tires and the road can influence the accuracy of the control system, so the fluctuation of the tilt becomes obvious during the process. 2. Only two sensors are used in the system, and some more parameters are worked out by calculating the integration of the sensor data, which reduce the accuracy of the control system. Next step, more factors should be considered in the kinematic model, and more devices are needed to enhance the leveling efficiency.

Fig. (7). Simulation result.

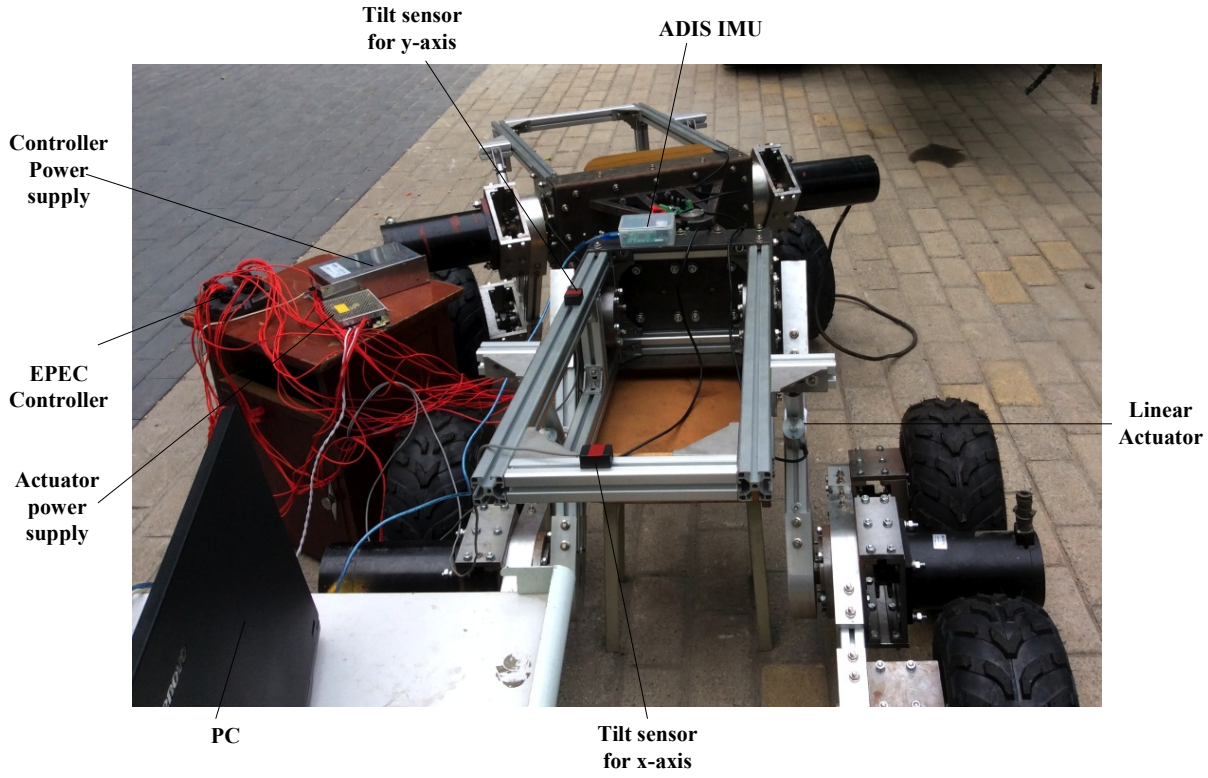

Fig. (8). Control system of the leveling test. 


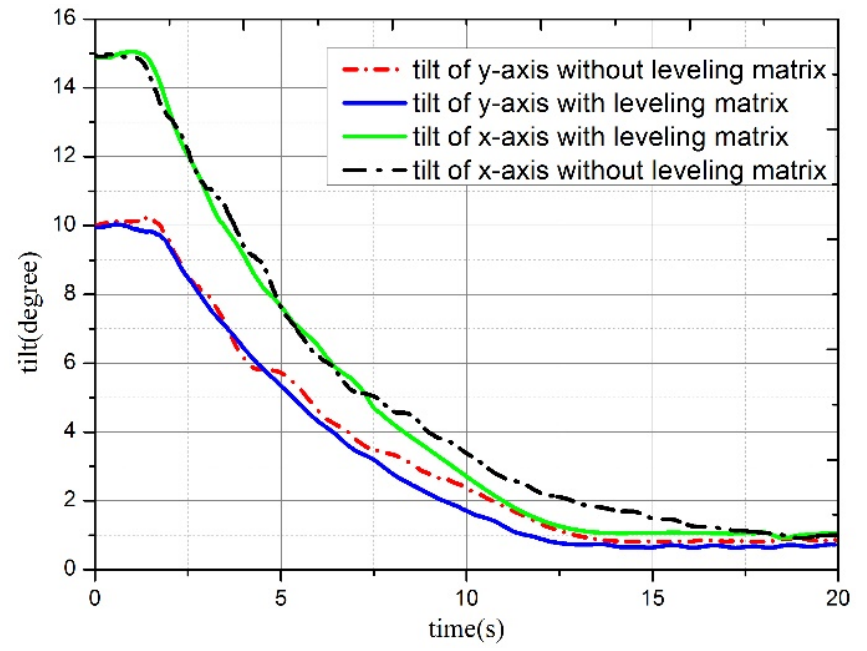

Fig. (9). Tilt-angle change curves of the test.

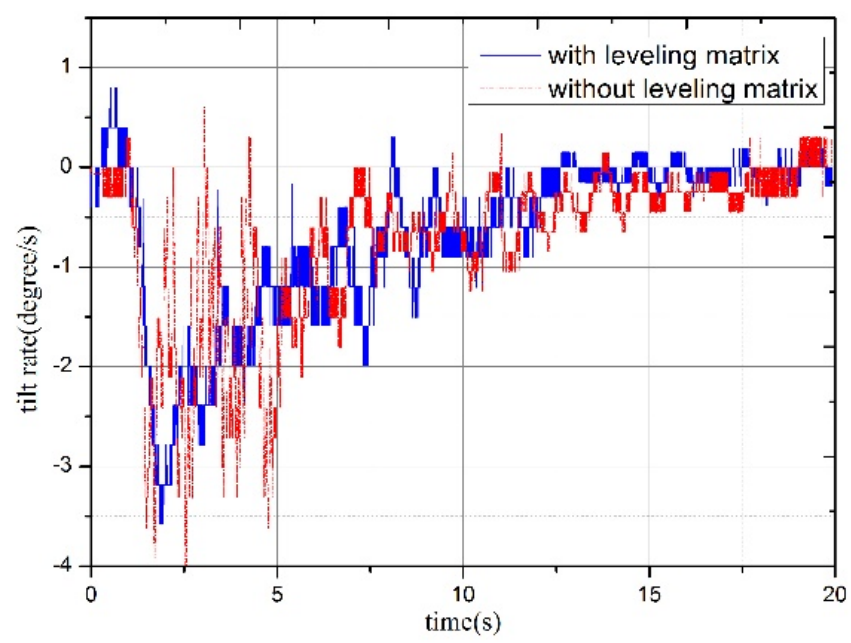

Fig. (10). X-axis tilt rate curves of the test.

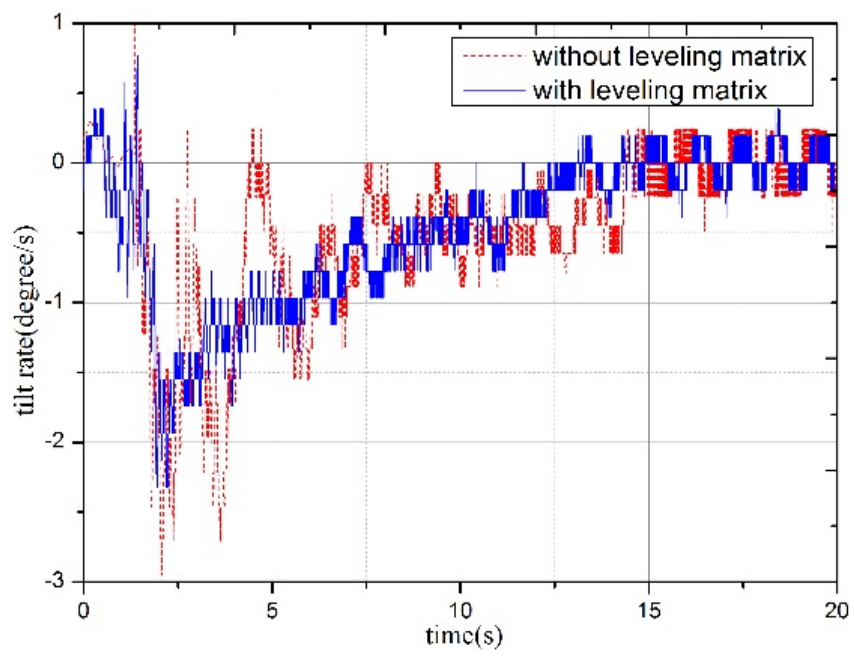

Fig. (11). Y-axis tilt rate curves of the test.
Table 2. Comparison of the performance.

\begin{tabular}{|c|c|c|}
\hline Performances & $\begin{array}{c}\text { Traditional } \\
\text { Algorithm }\end{array}$ & $\begin{array}{c}\text { Improved } \\
\text { Algorithm }\end{array}$ \\
\hline \hline Accuracy for $\mathbf{x}$-axis & 1.6 degree & 1.6 degree \\
\hline Accuracy for $\mathbf{y}$-axis & 1.4 degree & 1.4 degree \\
\hline Leveling time for $\mathbf{x}$-axis & $16.7 \mathrm{~s}$ & $13.2 \mathrm{~s}$ \\
\hline Leveling time for $\mathbf{y}$-axis & $14.3 \mathrm{~s}$ & $12.3 \mathrm{~s}$ \\
\hline $\begin{array}{c}\text { Times of obvious tilt } \\
\text { fluctuation for } \mathbf{x} \text {-axis }\end{array}$ & 8 & 6 \\
\hline $\begin{array}{c}\text { Times of obvious tilt } \\
\text { fluctuation for } \mathbf{y} \text {-axis }\end{array}$ & 4 & 1 \\
\hline
\end{tabular}

\section{CONFLICT OF INTEREST}

The authors confirm that this article content has no conflict of interest.

\section{ACKNOWLEDGEMENTS}

This work is supported by "the Fundamental Research Funds for the Central Universities TD2013-4. The authors would like to thank Professor Dr. Zheng Yili and Dr. Huang Qingqing for their important contribution to this work.

\section{REFERENCES}

[1] S. Nakajima, "Concept of a novel four-wheel-type mobile robot for rough terrain, RT-mover," In: 2009 IEEE/RSJ International Conference on Intelligent Robots and Systems, IROS, St. Louis, MO, United states, 2009, pp. 3257-3264.

[2] R. Siegwart, P. Lamon, T. Estier, M. Lauria, and R. Piguet, "Innovative design for wheeled locomotion in rough terrain," In: Intelligent Autonomous Systems - IAS-6, July 25, 2000 - July 27, 2000, Venice, Italy, 2002, pp.151-162.

[3] S. K. Jun, G. D. White, and V. N. Krovi, "Kinetostatic design considerations for an articulated leg-wheel locomotion subsystem," Journal of Dynamic Systems, Measurement, and Control, vol. 128, pp. 112-121, 2006

[4] S. Nakajima, and E. Nakano, "Adaptive gait for large rough terrain of a leg-wheel robot (1st report, gait strategy)," Nihon Kikai Gakkai Ronbunshu, C Hen/Transactions of the Japan Society of Mechanical Engineers, Part C, vol. 72, pp. 2926-2931, 2006.

[5] S. Nakajima, and E. Nakano, "Adaptive gait for large rough terrain of a leg-wheel robot $\left(2^{\text {nd }}\right.$ report, gait for an upward step)," Nihon Kikai Gakkai Ronbunshu, C Hen/Transactions of the Japan Society of Mechanical Engineers, Part C, vol. 72, pp. 2932-2939, 2006.

[6] S. Nakajima, and E. Nakano, "Adaptive gait for large rough terrain of a leg-wheel robot ( $3^{\text {rd }}$ report, gait for a downward step)," Nihon Kikai Gakkai Ronbunshu, C Hen/Transactions of the Japan Society of Mechanical Engineers, Part C, vol. 72, pp. 2940-2947, 2006.

[7] S. Nakajima, and E. Nakano, "Adaptive gait for large rough terrain of a leg-wheel robot ( $4^{\text {th }}$ report, gait for getting over an obstacle)," Nihon Kikai Gakkai Ronbunshu, C Hen/Transactions of the Japan Society of Mechanical Engineers, Part C, vol. 72, pp. 2948-2955, 2006.

[8] S. Nakajima, and E. Nakano, "Adaptive gait for large rough terrain of a leg-wheel robot (5 $5^{\text {th }}$ report, integrated gait)," Nihon Kikai Gakkai Ronbunshu, C Hen/Transactions of the Japan Society of Mechanical Engineers, Part C, vol. 72, pp. 2956-2963, 2006. 
[9] G. Besseron, C. Grand, F. B. Amar, F. Plumet, and P. Bidaud, "Stability control of an hybrid wheel-legged Robot," In: $8^{\text {th }}$ International Conference on Climbing and Walking Robots and the Support Technologies for Mobile Machines, CLAWAR 2005, September 13, 2005 - September 15, 2005, London, United Kingdom, 2006, pp. 533-540.

[10] X. Ding, K. Li, and K. Xu, "Dynamics and wheel's slip ratio of a wheel-legged robot in wheeled motion considering the change of height," Chinese Journal of Mechanical Engineering, vol. 25, pp. 1060-1067, 2012.

[11] V. SunSpiral, D. W. Wheeler, D. C. Clemente, and D. Mittman, "Development and field testing of the FootFall planning system for the ATHLETE robots," Journal of Field Robotics, vol. 29, pp. 483 $-505,2012$.

[12] T. B. Smith and D. Chavez-Clemente, "A practical comparison of motion planning techniques for robotic legs in environments with obstacles," In: $3^{\text {rd }}$ IEEE International Conference on Space Mission Challenges for Information Technology, SMC-IT 2009, Pasadena, CA, United States, 2009, pp. 155-162.

[13] V. SunSpiral, D. Chavez-Clemente, M. Broxton, L. Keely, P. Mihelich, D. Mittman, and C. Collins, "FootFall: A ground based operations toolset enabling walking for the ATHLETE rover," In: Space 2008 Conference, San Diego, CA, United States, 2008.

[14] Z. Jiangang, H. Dagui and L. Chaoshuang, "Research on dynamic model and control strategy of auto-leveling system for vehicleborne platform," In: International Conference on Mechatronics and Automation (ICMA), Harbin, China, 2007, pp. 973-977.
[15] Y. Wu, J. Sun, K. Zhang, F. Qiao, and H. Guo, "Intelligent leveling system of suspended access platform," In: 2010 International Conference on Modelling, Identification and Control, ICMIC 2010, July 17, 2010 - July 19, 2010, Okayama, Japan, 2010, pp. 676-681.

[16] F Ma, The Applied Study on Engineered Vehicle Used to Tunnel and Simulation Analysis on the Levelling of Suspension, Yanshan University, China, 2013.

[17] F. T. Thwaites, F. B. Wooding, J. D. Ware, K. R. Peal, and J. A. Collins, "A leveling system for an Ocean-Bottom Seismometer," In: MTS/IEEE OCEANS, Washington, DC, United States, 2005.

[18] B. Wang, Study on Automatic Leveling Control System of Vehicle Platform Based on Neural Network, Harbin Institute of Technology, China, 2012.

[19] Y. Feng and B. Chen, "Control system of automatically leveling of vehicle-borne radars," Huazhong Keji Daxue Xuebao (Ziran Kexue Ban)/Journal of Huazhong University of Science and Technology (Natural Science Edition), vol. 32, pp. 66-71, 2004.

[20] Y. Zhang, Research on Articulated Engineering Vehicles Overturning Stability and Anti-roll Warning Strategy, Jilin University, China, 2009.

[21] R. B. Jiao, C. Chen, M. Yuan, and F. P. Wang, "The study of automatically leveling control system on electromechanical vehicle stable platform," In: 2013 International Symposium on Vehicle, Mechanical, and Electrical Engineering, ISVMEE 2013, Taiwan, China, 2014, pp. 266-269.

[22] S.B. Niku, "Introduction to Robotics-Analysis, control Applications", Second Edition, Publishing House of Electronics Industry, 2011.

(C) Zhibo et al.; Licensee Bentham Open.

This is an open access article licensed under the terms of the Creative Commons Attribution Non-Commercial License (http://creativecommons.org/licenses/by-nc/3.0/) which permits unrestricted, non-commercial use, distribution and reproduction in any medium, provided the work is properly cited. 